\title{
Environmental assessment of Smart City Solutions using a coupled urban metabolism—life cycle impact assessment approach
}

Ipsen, Kikki Lambrecht; Zimmermann, Regitze Kjær; Nielsen, Per Sieverts; Birkved, Morten

Published in:

International Journal of Life Cycle Assessment

Link to article, DOI:

$10.1007 / \mathrm{s} 11367-018-1453-9$

Publication date:

2019

Document Version

Peer reviewed version

Link back to DTU Orbit

Citation (APA):

Ipsen, K. L., Zimmermann, R. K., Nielsen, P. S., \& Birkved, M. (2019). Environmental assessment of Smart City Solutions using a coupled urban metabolism—life cycle impact assessment approach. International Journal of Life Cycle Assessment, 24(7), 1239-1253. https://doi.org/10.1007/s11367-018-1453-9

\section{General rights}

Copyright and moral rights for the publications made accessible in the public portal are retained by the authors and/or other copyright owners and it is a condition of accessing publications that users recognise and abide by the legal requirements associated with these rights.

- Users may download and print one copy of any publication from the public portal for the purpose of private study or research.

- You may not further distribute the material or use it for any profit-making activity or commercial gain

- You may freely distribute the URL identifying the publication in the public portal 


\section{Environmental assessment of Smart City}

\section{Solutions using a coupled Urban Metabolism - Life Cycle Impact Assessment approach}

Kikki Lambrecht Ipsen a , Regitze Kjær Zimmermann ${ }^{\text {a,d }}$, Per Sievert Nielsen ${ }^{\text {b }}$, Morten Birkved ${ }^{\mathrm{c}}$

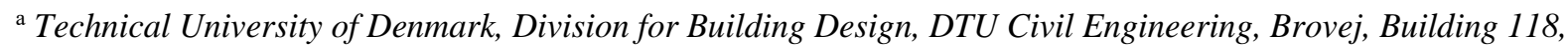
Kongens Lyngby, 2800, Denmark

${ }^{\mathrm{b}}$ Technical University of Denmark, Division for System Analysis, DTU Management Engineering, Produktionstorvet Building 424, Building 426, Kongens Lyngby, 2800, Denmark

${ }^{c}$ Technical University of Denmark, Division for Quantitative Sustainability Assessment, DTU Management Engineering, Produktionstorvet Building 424, Kongens Lyngby, 2800, Denmark

${ }^{d}$ Danish Building Research Institute, Aalborg University Copenhagen, A C Meyers Vaenge 15, DK-2450 Copenhagen SV, Denmark

\section{Abstract}

Purpose. The purpose of the study is to quantify the environmental performance of Smart City Solutions at urban system level and thus evaluate their contribution to develop environmentally sustainable urban systems. Further, the study illustrates how this quantification is conducted.

Methods. The case city chosen in our modelling is Copenhagen, where seven Smart City Solutions are introduced: Green Roofs, Smart Windows, Pneumatic Waste Collection, Sensorized Waste Collection, Smart Water meters, Greywater Recycling and Smart Energy Grid. The assessment is conducted using a fused Urban Metabolism (UM) Life Cycle assessment (LCA) approach, referred to as UM-LCA. The UM-LCA uses metabolic flows across an urban system as inputs and outputs in an LCA. All life cycle stages of the metabolic flows can be accounted for by using this approach and burden shifting from one stage to another is made quantifiable and hence transparent. The impact assessment is conducted using the ReCiPe method.

Results and discussion. The results obtained for the midpoint indicator, Global Warming Potential (GWP), shows reduced environmental performance effect at $75 \%$ relative to a business as usual reference scenario by introducing Smart Windows. Furthermore, the GWP indicator shows an environmental improvement of $10 \%$ for a Smart Energy 
Grid solution. Introduction of Pneumatic Waste Collection or Greywater Recycling reveals a minor negative performance effect of $0,76 \%$ and $0,70 \%$ respectively for GWP. The performance changes of in terms of GWP for the remaining solutions are so small, that these are expected to be within the uncertainty of the calculations. To obtain endpoint indicators (damages) the entire palette of ReCiPe indicators are included. The results of the endpoint indicator assessment yield a tendency similar to the one observed for climate change.

Conclusions. It is found that the implementation of Smart City Solutions generally have a negative influence on the environmental sustainability performance of an urban system. The limited positive influence from the Smart City Solutions is due to burden shifting from the direct impacts of the urban system to embedded impacts which are out of sight for most policy makers. The influence of the Solutions on Copenhagen is generally small, due to a focus on reducing in areas, that are not a large environmental burden in Copenhagen. The results are not sufficient to discard the idea of using Smart City Solutions to reduce environmental impacts, but highlight the importance of choosing solutions with the right focus and optimizing the design to best fit the intensions.

\section{Keywords}

Smart City, UM-LCA, Life Cycle Assessment, Urban Metabolism, Burden Shifting, Urban design, Urban systems

\section{Introduction}

Cities are expanding and increasing in numbers. Around the world people are migrating towards cities, creating more and larger urban areas. In the developed world $75 \%$ of the population live in urbanized areas and the number is still increasing (Larsen et al 2011). This number is lower in the developing countries, however, migration is happening at a higher rate here (Larsen et al 2011). It is estimated that every week more than one million people either migrate to or are born into cities in the developing world (Townsend 2013). More than half the world's population live in cities today and it is expected that this number will further increase in the coming decades.

At the same time technology is developing at a rapid pace and access to technology is also rapidly increasing. This is the basis for novel urban system developments such as the Smart City (SC). SC is a widely-used concept for cities, especially in Europe. The concept generally describes solutions which use technology of some form to improve the performance of the urban system.

These Smart City Solutions (SCSs) have different ways of improving the urban system. The smart technology is claimed to be able to improve social, governmental, economical, or environmental aspects of the urban system (Cocchia 2014; Nam et al 2011; Neirotti et al 2014; Townsend 2013). A general trend is that the SCSs can make the urban system 
more efficient. Such efficiency improvements include reducing energy use or reducing transport by using intelligent systems and data to optimize the efficiency of the system. Rethinking or optimizing an existing system by introducing a new technology so that the technology become more efficient is the approach that often frames the "smart" concept. These SCSs can reduce resource consumption of the urban system such as electricity, water and transport, as the increased effectiveness are intended to reduce energy consumption, whereby the direct emissions to the environment are lowered. However, implementing the SCSs also means that new products are introduced which may increase indirect emissions to the environment (e.g. emissions occurring in relation to the production of the smart technology and hence often far away from the urban system receiving the smart technology).

There is little research on the subject of the environmental burden induced by dedicated "smart" urban system technologies in the existing literature. The method used to conduct the assessment (see paragraphs 2.2) of the technologies, presented in our paper, has been developed and tested by Goldstein et al. (2013) on five different cities. Goldstein et al. (2013) found that the assessment method applied provides improved quantification of mass and energy flows through cities and that the method enables identification of the dominant sources of cities' environmental footprint. In terms of environmental assessments of Smart Cities or technologies qualifying as SCSs, assessments have been conducted previously, however the assessments have not been related to the urban system and thus not how the SCS may alter the environmental performance of urban systems (Malik et al. 2013; Zadeh et al. 2013; Yang et al. 2008; Villareal et al. 2004; Punkkinen et al. 2012; Memon 2007; Bianchini 2011). However, these previous assessments have proven valuable for our study, as they provide quantification of the (energy, water, and transport) saving potentials when a SCS is operating as a part of a city system. Qualitative analysis of case cities have previously been carried out accompanied by research on specific technologies. An example of such a qualitative analysis is the uncompleted ecocity, Caofeidian (China) presented by Joss et al. (2013), where the use of SCSs in the city is discussed. Furthermore, an analysis of Barcelona's initiatives to become a Smart City has been analysed at a strategic level (Bakıcı et al. 2012). The literature study hence reveals that no previous studies exists on how the implementation/application of smart technologies affects the environmental performance of the urban systems in which these technologies are implemented. The goal of this assessment is to gain insight into whether the SCSs can contribute to the development of environmental sustainable cities. In our paper, implementation of SCSs in existing urban systems is assessed to quantify the induced and/or avoided environmental impacts a technology may trigger when implemented in a specific urban system. Such impact/impact reduction trade-offs may arise from e.g. reducing energy consumption in the building operation stage by implementing SCSs to regulate energy consumption. In this study the environmental performance of seven SCSs 
implemented in the urban system of Copenhagen are tested. The solutions tested are all designed to either save energy (i.e. electricity) consumption in buildings during operation, reduce transport demands and/or reduce water consumption. Building energy and transport was chosen due to the significance of these urban metabolic flows (see Goldstein et al. (2013)) in relation to the environmental performance of cities, while "water" was chosen due its frequent occurrence in the environmental debate today. The SCSs connected to changing personal behavior, such as personal transport patterns, have not been included in our assessment since the method applied is not capable of taking personal transport into consideration. The 'smart'-aspects in the solutions tested are limited to use of Information and Communication Technology (ICT) and the chosen solutions have to state a potential for environmental savings when used. The solutions are evaluated using Life Cycle Assessment (LCA) coupled with Urban Metabolism (UM), to assess if the smart technologies lower the environmental burden of the urban system, or if their contribution is only to shift the burden within the smart technology solutions value chain (e.g. by moving impacts outside the urban system). In other words, whether the SCSs are exacerbating the environmental performance of the urban system.

\section{Methods}

\subsection{Case study}

The purpose of this study is to quantify environmental impacts of SCSs when implemented in an urban system. Therefor a case urban system has been selected and examples of SCSs selected. Copenhagen is chosen as the case urban system, and seven SCSs are selected and assessed. The SCSs selected are all associated with buildings in the urban system, including the supply of materials and resources to buildings and waste systems connected to them. A "business as usual" scenario is our reference and includes an assessment of the urban system without implementation of SCSs. In additional scenarios, the seven SCS are individually implemented on the system. The aim of this approach is to illustrate the effect of the individual solutions in reference-scale to the existing urban system.

\section{Urban system case}

Copenhagen is chosen as the urban system case because of its proximity to the Technical University of Denmark, availability of data and Copenhagen's ambitious environmental goals for the future years such as e.g. becoming $\mathrm{CO}_{2}$ neutral by 2025 (City Hall 2009). The boundaries of the system are defined by the geographical boundaries of the city of Copenhagen, including the municipal of Copenhagen and the municipal of Frederiksberg, see Figure 1. In the following the geographical area occupied by the urban system will simply be referred to as Copenhagen. The reference year in our analysis is 2013, as this is the most recent year with actual (non-projected) data available at the initiation of 
the work. In the beginning of the third quarter of 2013 the population of Copenhagen was 664.338 (Danmarks statistik

2013 ) and it occupied an area of $85,2 \mathrm{~km}^{2}$ (Danmarks statistik 2016). It results in a population density of 7800 citizens $/ \mathrm{km}^{2}$.

\section{Smart City Solutions}

A considerable number of SCSs exists. The chosen solutions are therefore limited to solutions intended for buildings that rely on and/or make use of ICT. This means that the relevant SCSs are limited to acting on the building or the supply of materials and resources and the connected waste systems. Relying on and/or making use of ICT means that the smart/technology aspect is fulfilled. Furthermore, a relevant SCS must claim to improve the environmental performance (i.e. the solutions could yield increased saving potential when implemented in the city), as this is a basis for the investigation.

Furthermore, a relevant SCS must be implementable in an urban system, but not necessarily be a dedicated urban solution that functions in urban environments exclusively. Finally, the solution must be beyond the ideation phase and well documented/described, to assure a sufficient data quality/availability, and the selected solutions must be relevant to Copenhagen in terms of climatic conditions.

Seven solutions have been identified to fulfill all the listed criteria and they are summarized in table 1 . The solutions are split into four domains: Building, waste, water, and power. Even though the solutions are within the same subject and all fulfill the same criteria, they are still very different. Some solutions (such as Sensorized Waste Collection (SWC), Smart Water Meter (SWM) and Smart Energy Grid (SEG)) work by adding an ICT element to existing mechanical systems, while others require additional installation of a new mechanical system where the ICT is pre-installed (e.g. Pneumatic Waste Collection (PWC)). The solutions also work at different urban levels. Some are operating at a building level (e.g. Green roofs (GRo), Smart windows (SWi) and Greywater Recycling (GRe)), while other are operating at urban system or city level, e.g. the waste technology. The seven SCSs are implemented individually on the case city, Copenhagen, resulting in seven scenarios.

\subsection{Urban Metabolism Coupled with Life Cycle Assessment}

UM is a 'big picture' environmental performance quantification of urban regions (Kennedy et al 2011). UM accounts for the consumption related flows of the city: The inputs, outputs and storage of energy, water, nutrients, materials and wastes, as shown in Figure 2. It is possible to calculate the urban metabolism using several methods (Pincetl et al 2012), 
however, the methods are too complex to both calculate and communicate, or too simple to provide reliable results (Goldstein 2013). A combination of UM and Life Cycle Assessment (LCA) have shown to be a relevant method (Goldstein 2013). LCA accounts for exchanges between the technosphere and ecosphere through all the life cycle stages of a service like the services provided by the metabolic flows of an urban system. By using the LCA methodology in combination with the UM all life cycle stages in a metabolic flow are accounted for, and burden shifting from one stage to another is made transparent. Furthermore, the LCA framework is far more developed than UM, for instance in terms of standardisation; e.g. ISO standards exist for LCA (ISO 2006a; ISO 2006b), as well as a user guidelines (European Commission 2010). This makes the assessment form reproducible, more credible and transparent compared to UM. Moreover, databases have been developed containing datasets that accounts for elementary flows of unit processes, easing the use of LCA framework compared to UM.

Fused UM-LCA uses the metabolic entity (i.e. the urban system) as offset for the LCA. This is illustrated in Figure 3. The LCA methodology is intended to account for process induced elementary flows in all life cycle stages, contrary to the UM. Hence for the LCA it is not important to distinguish between processes in a metabolic flow which occur inside or outside the urban system. When a SCS is introduced, the altered urban system and altered metabolic flows are assessed following the LCA framework considering elementary flows in all life cycle stages. This is illustrated in Figure 4. In the operation stage, the SCS is most often expected to provide a consumption saving, due to avoided metabolism. The metabolisms (or LCIs in LCA terms) for Copenhagen and for the SCSs can be seen in Supporting Information to this paper.

\subsection{System boundaries}

When relying on UM-LCA the assessment includes all lifecycle stages of the considered metabolic flows from cradle to grave. The system boundaries are illustrated in Figure 5, where the excluded aspects are marked with red. The direct impacts from the urban system and hence from the SCSs include consumption of electronics, food, tourism, buildings, power, consumer goods, water and finally transport and freight taking place inside Copenhagen. The embedded impacts include ground water extraction, raw material extraction, agriculture, power production, production in general and transport between phases and sub suppliers. Due to lack of data on construction phase of buildings, installation and of the actual SCSs, and data storage for all the data delivered/used by the SCSs are excluded. The exclusion of SCS installation and data storage is expected to lead to underestimation of the impact potential for the SCSs. The exclusion of building construction phase in the calculations is expected to lead to an underestimation of the impact potential for 
all scenarios. Furthermore, the embedded impacts resulting from tourism in Copenhagen involving transport of tourists to and from Copenhagen, mainly via ship or aircraft, have been excluded also due to lack of data. Exclusion of embedded impacts from tourism might also lead to an underestimation of the impact potential for all scenarios.

\subsection{System modeling}

The modelling is aimed at assessing the change in the system which occurs when an SCS is introduced to the urban system, in alignment with the intended purpose of our assessment. In this way, it is possible to quantify how the individual SCS affects the urban system's environmental performance. The modeling and quantification of the urban system inventory is done in $\mathrm{GaBi}$, version 7.2.1. The database used is Ecoinvent 3.1. In our case, a process-based LCA with a consequential modeling LCA approach is used. A consequential modeling approach is obvious to use, as the SCSs have an indirect impact on the environmental performance of the urban system by reducing various metabolic flows. The consequences of these impact changes on the city are assessed and quantified. However, GaBi does not allow for a consistent consequential modeling approach with the Ecoinvent database, and therefore attributional modeling using allocation at the point of substitution (APOS) is applied in the Ecoinvent database (background system). In accordance with the consequential modeling approach multifunctional processes are modelled using system expansion in the foreground system. This means that the system boundaries are expanded to include the life cycle inventory of the by-product(s). This is done for the waste scenario cases when incineration of a product yielded heat and/or electricity. In these cases, system expansion includes the production of heat and electricity as avoided productions, thereby reducing the impact potentials of the waste process. System expansion is also conducted when products are recycled. The processes used to model the metabolic flows in the city and the SCSs can be seen in the Supporting Information to this paper.

\section{Implementation of Smart City Solutions in the City}

Each solution is assessed in a Copenhagen context, and evaluated in accordance with how implementation of a given SCS may affect the environmental performance of the urban system. Each solution is implemented at $100 \%$ and each solution one at a time, meaning that e.g. in the GRo scenario, Green Roofs is the only solution implemented and it is implemented $100 \% .100 \%$ implementation does, however, not mean that e.g. all roofs are converted to green roofs, it is merely an estimation of the largest realistic implementation of Green Roofs in Copenhagen, see Figure 6. For example, an investigation conducted by the municipality of Frederiksberg (Frederiksberg kommune 2011) identified the area 
fraction of flat roofs in Frederiksberg suitable for installation of Green Roofs. This area fraction is used and scaled up to represent Copenhagen.

\subsection{Functional unit}

We compare Copenhagen in a business as usual scenario with scenarios where the various SCSs are implemented. The functional unit is to Provide an urban area of $\underline{85,2 \mathrm{~km}^{2}}$ with a population of 664000 citizens for a duration of 1 year. The year investigated is 2013. The functional unit is defined for an urban area and its population. However, the function of one urban area is by nature never identical to the function of another urban area. Though other urban areas can have similar population densities and similar size, the positioning properties of the system will be different, i.e. quality related positioning properties such as economic and social quality as well as more physical related properties such as access to supplying networks (water and electricity etc.). It is impossible to compare two urban areas, because they will never provide the same exact services. Therefore, the analysis is not used to compare one urban area to another urban area. Rather than comparing two different urban areas, our analysis compares the same urban system, with (slightly) different properties. As previously mentioned, we compare the urban system in its current state (reference scenario) with the same system where a SCS is implemented (GRo scenario, SWi scenario, PWC scenario, SWC scenario, SWM scenario, GRe scenario, SEG scenario). This type of assessment should yield an understanding of the influence of each SCS on the environmental performance of the city.

\subsection{Assumption and limitations} has limitations, that should be considered when the results of the UM-LCA are assessed. The UM-LCA is only useful with the right geographical boundaries and with the correct functional unit as discussed by Goldstein et al. (2013). This is because the urban-scale in the analysis might not be representing all the subsystems which affect the metabolic flows. Another issue is how stocks in the city is handled i.e. how the End of Life (EoL) of the stock is modelled. Stocks could for instance be building stocks, where the EoL is reached many years into the future. The final issue, not related to the choice of method or the modelling, is the limited data availability. It is not always possible to find sufficient, high quality data. In some situations, we have had to use alternative data and assumption to conduct the full assessment. The data for Copenhagen are mainly based on waste data. This means that the data does not account for the built-in delay in the metabolism, because products pile up in the urban system (also known as stock). For the energy, water, transport, and food consumption flows, the data are both site-specific (Copenhagen and Denmark) and time-specific 
(2013). Data on raw material extraction, material production and assembly are general data from the Ecoinvent database. For each SCS, the data for metabolic savings (electricity, water, transport) when the SCS is implemented, is primarily from independent studies. Material consumption for each SCSs is obtained primarily from suppliers. All the data used, are aiming at covering the optimal geographical, technological, and temporal context and thus representativeness. However, there are limitations to the coverage; the geographical location for processes outside Copenhagen is unknown, while the metabolic entity and the EoL stage takes place in Copenhagen. The technology applied in the EoL stage happens in the future and is therefore also unknown. Thus, general data from the Ecoinvent the temporal coverage, everything is modelled as taking place in 2013 . The model has been built around the Copenhagen waste statistics from 2013, and the consumption is extrapolated from this. However, in reality not all processes take place in 2013, but must have taken place before (e.g. production of the SCSs and related raw material extraction) and after (EoL for SCSs).

This introduces an unknown level of uncertainty to the model, that cannot be addressed because the uncertainty for each

\subsection{Impact assessment method}

250 Characterizing LCI data into impact potentials which cover a range of impact categories can be done using several Hierarchist $(\mathrm{H})$ perspective. The inventory data is initially classified to elementary flows and subsequently characterized to emissions both using the ReCiPe method. In $\mathrm{GaBi}$ there appears to be an error related to impact potentials belonging to Ionized Radiation amounting to a factor $1,0000010^{6}$ (i.e. corresponding to a unit conversion error). This error has been corrected in the results. Weighting and aggregating of the results into a single score is not carried out, because weighting has no real effect on the results (Kalbar et al 2016) and hence the decision support value, and because ISO recommends not to use weighting in LCA's intended for public disclosure (ISO 2006b).

The ReCiPe method provides a broad specter of midpoint impact categories, 18 categories in total. In this article, we provide results for the Global Warming potential (GWP) as the only midpoint category along with the three endpoint 
categories; damage to human health, damage to resources, and damage to ecosystems. We have chosen the midpoint results for GWP as the only midpoint category to relate to, simply because of the significant focus on $\mathrm{CO}_{2}$ emission (reduction) in society and at policy level in many cities knowing that this does comply to ISO-14040 (ISO $2006 \mathrm{a})$. Copenhagen, in particularly, has a goal of becoming $\mathrm{CO}_{2}$ neutral in 2025 (City Hall 2009), hence their sustainability goals are very much focused on $\mathrm{CO}_{2} /$ climate change. All ReCiPe midpoint impact categories (see table 2) are calculated and presented in the supporting material.

\section{Results}

Figure 7 a) illustrates the estimated GWP from implementation of each of the seven SCSs in Copenhagen. The difference in the results between the reference scenario and the scenarios with the individual SCSs implemented are less than $1 \%$ for most of the SCSs. The GWP results reveal that 4 of the 7 solutions have a negative impact on the environmental performance of the urban system, and that most systems do not have a significant change in impact. The results for the endpoint categories presented in Figure 7 b), c) and d) generally exhibit the same tendency as the GWP midpoint results, thus indicating that the aggregated impact potentials follow the same tendency as the GWP midpoint. The main contributors to the impact potentials (obtained by hotspot and sensitivity analysis) are listed in Table 3 . While the change in impact potential for the results shown in figure 7 a) to d) are shown and commented on in table 4. The impact potentials calculated with the individual SCSs implemented are generally lower compared to the reference scenario for the operation stage flows. It indicates that if the implementation is seen from a sole urban system operation point of view the SCSs have a positive impact on the environmental performance of the urban system. However, the impact potential trend changes when we include the embedded impacts of the material components needed to produce the SCSs. For other solutions, the operational stage flow is simply substituted with another operation stage flow, e.g. for the PWC, where transport is saved, but substituted with electricity use. A more detailed analysis of the results furthermore shows that the tendency when a new mechanical system is introduced is that the main contributor of impacts and damages is the materials needed for the mechanical system and hence the embedded impacts. For the SCSs that rely on ICT the components providing the ICT functionality (such as sensors and controllers) are the main contributors to the (embedded) impacts. The savings in consumption obtained when the SCS is implemented are observed in the operation stage flows within the urban system and hence the main contributors to the reduction of e.g. the GWP related impacts are the savings obtained by using the SCSs. 
291 The GWP midpoint results show that an improvement of the environmental performance of Copenhagen is to be

expected by adoption of SEG, SWMs, and SWC. Contrary, a decrease in environmental performance is to be expected by adoption of the remaining solutions. The results for the remaining ReCiPe midpoint categories are presented in the Supporting Information to this paper. The results of the remaining ReCiPe midpoint categories show in most cases the same tendencies as are observed for the GWPs. However, SWMs show a worsening of the performance of the urban system in 11 of the 18 categories and hence a general decrease of the environmental performance of the urban system, contrary to the results obtained for the GWPs. This indicates that even though the GWP is a generally accepted and used indicator for sustainability and environmental performance, it is considered advisable not to depend on this indicator solely, since this might result in burden shifting among impact indicators. Overall, SWMs have very little effect on the performance potential of the urban system. The relative urban system performance changes are very small when adopting SWMs. Not only in terms of GWP, but for all the impact categories. The same goes for GRo and SWC. The study shows that the three previously mentioned SCSs (SWMs, GRos and SWC) have no influence on the environmental performance of the urban system of Copenhagen. However, it should still be kept in mind that there may be a level of uncertainty associated with the results which is unknown. The impact reductions may very well be lower than the uncertainty, which we have not been able to quantify.

\subsection{Endpoint}

It is observed that the endpoint scores exhibit the same general trends as the GWP midpoint indicator when the damage potential expected from implementation of the SCSs is analyzed. It should be mentioned that the GWPs contribute to the endpoint indicators for human health and ecosystem damages. Even though the same general impact trends are observed for both the GWPs and the endpoint scores, there is a difference in the relative changes. For the SWi and the the GWP, a more extreme picture in terms of environmental performance change for the SCSs is observed. For the other SCSs, the GWP is not more extreme than the endpoint scores, and hence the GWP exhibit the same the as the endpoint scores. From the impact potentials, both at midpoint level and the damage potential at endpoint level, it is possible to conclude that the only SCS that uniformly improves the environmental performance of Copenhagen is SEG. Judged across both midpoints and endpoints the environmental burden of Copenhagen appears uniformly to increase by adoption of the SWi, PWC, and GRe. Judged across both midpoints and endpoints the results are inconclusive for GRo, 
SWC, and SWM. The reason the three last-mentioned SCSs (GRo, SWC and SWM) are inconclusive is due to the relative minute change influence on almost all the midpoint impacts categories. This influence is (very) small and taking the overall assessment uncertainty into account we claim that there is no clear tendency to whether the influence of implementation of these solutions will lead to a better or worse environmental performance of Copenhagen. In addition, since some midpoint impact categories indicate improvement, while others indicate worsening, the overall picture becomes inconclusive and dependent on weighing of the midpoint indicators. Because of this inconclusive picture and due to the uncertainties connected to this assessment method as such, it is not possible to conclude any clear/uniform tendency from these three SCSs.

\subsection{Burden shifting}

328 All solutions reduce impact potentials in operation stage, however, as discussed; most solutions increase the overall environmental burden of the urban system. This phenomenon is caused by a burden shift within the system, as can be seen from the results of the hotspot analysis shown in Table 3. The impacts are shifted from the operation stage to the raw material and production stages as illustrated in Figure 8. The burden is hence no longer mainly induced within the urban system as direct impacts, but rather embedded in the products/materials where the actual impact location is more uncertain. In some cases, larger impact shifts occur within the operation stage and hence within the urban system. This is in the cases where a SCS has high energy consumption. Here one operation stage reduction is substituted by an saving is substituted by increased consumptions, more of the major contributors for the total environmental impact occur in the urban system. By occurring in the urban system as a direct impact there is a greater chance that this kind of burden shift is accounted for.

The underlying problem with this burden shifting is an overestimate of real achieved $\mathrm{CO} 2$ emissions reduction. For instance, the focus is on the reduction of direct impacts: building energy (both heat and electricity), transport, and household waste in the climate plan for Copenhagen (City Hall 2009). When we only focus on these direct impact reduction potentials, it is very likely that embedded impacts are forgotten or not accounted for. In the case of embedded impacts, the environmental burdens are not removed, but just moved from the city to a background system, which is not accounted for (properly). Based on the assessments conducted here one important issue emerges: great care should be taken when implementing SCSs to achieve environmental goals, as it is not necessarily certain that there are any environmental gains from implementing them, seen from the life cycle perspective where the entire value chain of SCS 
is covered. If the assessments of the SCSs are limited to the direct impacts, it can look as though implementation may by a good idea and a step towards a sustainability goal. The general attention SCSs attract combined with the results presented in this paper highlights the importance of including the embedded impacts when assessing the environmental burdens of large system such as an urban system. Not only when we consider implementing SCSs, but also when we look at other types of urban system alterations.

\subsection{Copenhagen}

In the assessment, we have also conducted a hotspot analysis of Copenhagen, to find the major drivers for the total environmental burden of Copenhagen without the implementation of any SCSs. The results of this can be seen in the Supporting Information to this paper. It is observed that the main contributors to urban system impacts are food consumption, consumption of electronics, mobility or transport, and construction activities. This is approximately the same results as found by Goldstein et al. analyzing five different cities (Goldstein et al 2013), except that Goldstein et al. (2013) found that a main contributor is building energy and not electronics consumption as found in our analysis. The reason why building energy has been included in our study is that some of the SCSs are intended to reduce consumption hereof. Since Copenhagen differs from cities analyzed by Goldstein et al. especially in terms of embedded impacts of specific flows, the deviation in the main contributors for the environmental burden, seems valid. A reason why the building energy is not a main contributor in Copenhagen, while the literature suggest that it is a main contributor for other cities around the world, may be that there has been a large focus in recent years on greening of the energy grid and on reducing electricity and heating needs in buildings, amongst others through better insulated buildings. Because a considerable fraction of the energy system in Denmark consists of renewable energy sources, the energy supply of Copenhagen is consequently less dependent on fossil fuels. The building energy in Copenhagen therefore contributes to less of an impact potential than the cities assessed in Goldstein et al. (2016). From the main contributors found in our analysis, it is evident that none of the SCSs have (significant) saving influence on any of the metabolic flows that are considered the main impact contributors. At the same time the SCSs contribute to an increase in the consumption of electronics, which is a major contributor for the total environmental burden of Copenhagen. Thereby it could be beneficial to do further work assessing SCSs that are focused on savings of the metabolic flows that are major contributors for the environmental burden of Copenhagen.

The fact that building energy is a main contributor for the total environmental burden for other cities than Copenhagen highlight the point that it might be beneficial for the entire understanding of the SCSs influence on urban systems to 
implement them in various types of cities, which have different major impact contributors. Furthermore, it would be interesting to analyze whether some of the SCSs would perform different/better under other climatic conditions than the Danish.

\subsection{The scale of the analysis}

The change in impact potentials for Copenhagen induced by the SCSs is calculated and shows that the changes for most SCSs are quite small. This is because the (urban) system of Copenhagen is very large, and the changes induced by a SCS is not significant in comparison to the entire urban system. In other words; the potential of the SCSs is not grand. Even though the impact changes from an SCS implementation is small; it might be that if one of the SCSs is implemented in Copenhagen in real life, the resulting changes could be even smaller. This is because our assessment assumes a $100 \%$ implementation of SCSs in Copenhagen, which might not be a realistic scenario. Nevertheless, the $100 \%$ implementation scenarios provide an estimate of the maximum expectable benefit from an SCS implementation. We consider the SWi as an example. In this scenario, it is assumed that all windows in commercial buildings are changed or altered to include the electrochromic film (ITO material). As is obvious to most readers; there are other (also "unsmart") kinds of window shading solutions available, both for internal and external shading which provide the same service as the SWi and many commercial buildings might already have such an ("unsmart") shading system. Because alternatives may already be installed it is unlikely that a $100 \%$ implementation could happen, which once again highlight that our calculations are to be regarded as maximum expected benefit.

\subsection{Limited number of Smart City Solutions}

A limited number of SCSs are assessed. The scenarios indicate that SCS adoption is not necessarily to the benefit of environmental sustainability performance of an urban system, even though a SCS might appear beneficial from the direct saving potentials. However, the tendency observed from our results is not convincing enough to give a general environmental sustainability picture of SCSs given that some of the solutions show improvement and that the impact on the environmental performance of city in some cases is very small. As indicated by the hotspot and sensitivity analysis in Table 3, there are certain parameters for each SCS that largely controls the environmental burden of the assessed SCSs. Hence, a reduction of such parameters and/or a significant urban system flow saving when implemented, could contribute to a different picture on SCSs than the picture emerging from our assessment. Focal points in the sustainability refinement of the SCSs could be: careful examination of when and where it is necessary to use ICT components, especially if the savings from operation are of limited proportions. Such basic assessments are relevant 
because our hotspot analysis revealed that the ICT (e.g. sensor, controller) components are hotspots for some of the SCSs. And for most SCSs, it is possible to remove the ICT components from the solutions and still have the SCSs provide the same service. Another focal point is minimization of the electricity consumption (in our case relevant for PWC and GRe), and finally reducing the general material consumption, especially for the materials that are based on scarce resources. Another issue worth considering is the possibility of making the SCSs repairable, because the ICT components, if broken, are usually replaced instead of repaired.

Even though the SCSs save consumption, of for instance electricity, and claim to improve the sustainability performance of an urban system, the solutions are not necessarily implemented with the purpose of reducing the environmental impact. The purpose of an SCS implementation could also be other improvements of the urban systems, such as improved comfort from using SWis, reducing traffic from waste collection, or better water management in cities to reduce overload of existing sewer network from GRo. In other words, motivation of the implementation could hence be on social or economic aspects of the urban system. However, these aspects are not part of our assessment, and we can therefore not say anything about the SCSs performance on these indicators. These benefits could be assessed in future work. The fact that there can be other motives than potential environmental gains for implementing the SCSs, only highlights the importance of transparent communication of motives for implementing SCSs.

\section{Conclusions}

This study has tested the influence that seven different Smart City Solutions (SCSs) have on an urban system in a UMLCA perspective. The urban system investigated is Copenhagen. It is found that only one of the SCSs reduce the environmental burden of Copenhagen; the SEG. The solutions SWi, PWC and GRe are found to increase the environmental burden of Copenhagen, while the results for the solutions GRo, SWC and SWMs are inconclusive, because the influences they have on Copenhagen are overshadowed by uncertainties in the model. This illustrates, that the SCSs analyzed here have limited ability to alter the environmental sustainability performance of an urban system in a positive direction. The limited positive influence from the SCSs is due to burden shifting from the direct impacts of the urban system to embedded impacts which are out of sight for most policy makers. At the same time, the savings in metabolic flows that the SCSs provide, are not necessarily on the exact flows that are major contributors to the sustainability performance of Copenhagen. This lack of focus on impact contribution might be why the assessed SCSs do not improve the performance of Copenhagen. Even though the beneficial influence of the SCSs is limited, there are 
environmental burden. Further work on altering/designing the SCSs so they use less material and less ICT, testing of the

influence of other solutions, and testing of the influence on other cities could be conducted.

Baetens R, Jelle BP, Gustavsen A (2010) Properties, requirements and possibilities of smart windows for dynamic daylight and solar energy control in buildings: A state-of-the-art review. Sol Energy Mater Sol Cells 94:87-105. http://dx.doi.org/10.1016/j.solmat.2009.08.021

Bakıcı T, Almirall E, Wareham J (2013) A Smart City Initiative: The Case of Barcelona. J of the knowl econ. 4: 135 148. http://doi.org/10.1007/s13132-012-0084-9

Bianchini F, Hewage K (2012) How “green” are the green roofs? Lifecycle analysis of green roof materials. Build Environ. 48:57-65.http://dx.doi.org/10.1016/j.buildenv.2011.08.019

Britton TC, Stewart RA, O’Halloran KR (2013) Smart metering: Enabler for rapid and effective post meter leakage identification and water loss management. J Clean Prod. 54:166-76. http://dx.doi.org/10.1016/j.jclepro.2013.05.018

Cocchia A (2014) Smart and Digital City: A systematic Literature Review. In Dameri, R.P and Rosenthal-Sabroux C. (eds) Smart City. Springer, Switzerland, pp 13-43

Chou J-S and Ngo N-T (2016) Smart grid data analytics framework for increasing energy savings in residential buildings. Autom Constr 72:247-257. http://www.sciencedirect.com/science/article/pii/S0926580516000030

City Hall (2009) Carbon Neutral by 2025 - Copenhagen Climate plan. City of Copenhagen, The Technical and Environmental Administration, City Hall. https://www.energycommunity.org/documents/copenhagen.pdf

Danmarks statistik (2013) Folketal den 1. i kvartalet efter køn, alder, civilstand, område of tid. Danmarks statistik http://www.statistikbanken.dk/statbank5a/selectvarval/saveselections.asp. Accessed 30 November 2016

Danmarks statistik (2016) Areal efter område og tid. Danmarks statistik

http://www.statistikbanken.dk/statbank5a/selectvarval/saveselections.asp. Accessed 30 November 2016

Dansk skraldesug ApS (2016) Minimax. Dansk skraldesug ApS.

http:/www.danskskraldesug.dk/Webnodes/da/Web/Dansk+Skraldesug/Affaldssystemer/Minimax++\%28fuldt+nedgrav et $\% 29$. Accessed 30 November 2016

EcoGrid EU (2016) EcoGrid EU - A Prototype for European Smart Grids. Deliverable D6.7 Overall evaluation and conclusion. EcoGrid EU. http://www.eu-ecogrid.net. Accessed 30 November 2016

Enevo (2016) Products. Enevo. http://www.enevo.com/products/. Accessed 30 November 2016

Envac ab (2009) Vakuumteknologi. Envac. http:/www.envac.dk/produkter-ydelser/vores-teknik/teknologien-bagaffaldssug. Accessed 30 November 2016

European Commission (2010) International Reference Life Cycle Data System (ILCD) Handbook --

General guide for Life Cycle Assessment -- Detailed guidance. Publication Office of the European Union, Luxembourg http://lct.jrc.ec.europa.eu/pdf-directory/ILCD-Handbook-General-guide-for-LCA-DETAIL- online-12March2010.pdf

ISO (2006a) ISO 14040:2006 - Environmental management - Life cycle assessment - Principles and Framework. International Standards Organization, Switzerland 
ISO (2006b) ISO 14044:2006 - Environmental management - Life cycle assessment - Requirements and guidelines. International Standards Organization, Switzerland

Frederiksberg kommune (2011) Analyse for potentialet for grønne tage, solceller og tagvindmøller. Frederiksberg kommune. https://www.frederiksberg.dk/sites/default/files/meetings-appendices/E58F7213-982F-483D-93C59C2EBA08C2DE/2251635-2329574-1.PDF. Accessed 30 November 2016

Free ES, Selkowitz SE, Clear RD, DiBarolomeo DL, Klems JH, Fernandes LL, Ward GJ, Inkarojrit V and Yazdanian M (2006) A Design Guide for Early-Market Electrochromic Windows. Lawrence Berkeley Natl Lab http://escholarship.org/uc/item/3mm8j7q1\%0ACopyright. Accessed 30 November 2016

Gutierrez JM, Jensen M, Henius M and Riaz T (2015) Smart Waste Collection System Based on Location Intelligence. Procedia Comput Sci 61:120-7. http://dx.doi.org/10.1016/j.procs.2015.09.170

Goldstein B, Hauschild M, Fernández J, Birkved M (2016) Testing the environmental performance of urban agriculture as food supply in northern climates. J Clean Prod 135:984-94

Goldstein B, Birkved M, Quitzau M-B, Hauschild M (2013) Quantification of urban metabolism through coupling with the life cycle assessment framework: concept development and case study. Environ Res Lett 835024 Hauber-Davidson G, Idris E (2006) Smart Water Metering. Water 33.3: 38-41

Hu Z, Li C, Cao Y, Fang B, He L and Zhang M (2014) How smart grid contributes to energy sustainability. Energy Procedia 61:858-61 http://dx.doi.org/10.1016/j.egypro.2014.11.982

ITU, International Telecommunication Union (2014) Smart water management in cities. International Telecommunication Union. https://www.itu.int/en/ITU-T/focusgroups/ssc/Documents/Approved_Deliverables/TRSWM-cities.docx Accessed 30 November 2016

Jefferson B, Laine a, Parsons S, Stephenson T and Judd S (2000) Technologies for domestic wastewater recycling. Urban Water 1:285-92

Joss S, Molella A (2013) The Eco-City as Urban Technology: Perspectives on Caofeidian International Eco-City (China). J of urban technology 20: 115-137. http://doi.org/10.1080/10630732.2012.735411

Kalbar P, Birkved M, Nygaard S, Hauschild M (2016) Weighting and Aggregation in Life Cycle Assessment: Do Present Aggregated Single Scores Provide Correct Decision Support? J Ind Ecol 0:1-10 Online: http://doi.wiley.com/10.1111/jiec.12520

Kamstrup (2015) Data sheet Siemens MAG 8000 with READy Gateway. Kamstrup. http://products.kamstrup.com/. Accessed 30 November 2016

Kamstrup (2016a) Non-Revenue Water - understanding and working proactively with Non-Revenue Water. Kamstrup. https:/www.kamstrup.com/en-en/business-areas/water-metering/non-revenue-water. Accessed 30 November 2016

Kamstrup, (2016b), The digital water utility - white paper on the potential of smart metering. Kamstrup.

https:/www.kamstrup.com/en-uk/business-areas/water-metering/the-digital-water-utility. Accessed 30 November 2016

Kennedy C, Pincetl S, Bunje P (2011) The study of urban metabolism and its applications to urban planning and design. Environ Pollut 167:184-185. http://dx.doi.org/10.1016/j.envpol.2010.10.022

Larsen H, Petersen L (2011) Risø Energy Report 10 : Energy for smart cities in an urbanised world. Danmarks Tekniske Universitet, Risø Nationallaboratoriet for Bæredygtig Energi. http://orbit.dtu.dk/en/publications/risoe-energyreport-10--energy-for-smart-cities-in-an-urbanised-world(4e125ec3-2089-483b-a1bf-4840807be6b1).html. Accessed 30 November 2016 
Lazarova V, Hills S, Birks R (2003) Using recycled water for non-potable, urban uses: A review with particular reference to toilet flushing. Water Sci Technol: Water Supply 3:69-77

Malik AS, Bouzguenda M (2013) Effects of smart grid technologies on capacity and energy savings - A case study of Oman. Energy 54:365-371. http://dx.doi.org/10.1016/j.energy.2013.03.025

Mamun MAA, Hannan MA, Hussain A, Basri H (2014) Real Time Bin Status Monitoring for Solid Waste Collection Route Optimization. Eng Technonogy. http://doi.org/10.1049/cp.2014.1077

Memon FA, Zheng Z, Butler D, Shirley-Smith C, Lui S, Makropoulos C, Avery L (2007) Life cycle impact assessment of greywater recycling technologies for new developments. Environ Monit Assess 129:27-35

Nam T, Pardo TA (2011) Conceptualizing smart city with dimensions of technology, people, and institutions. Proc 12th Annu Int Digit Gov Res Conf Digit Gov Innov Challenging Times. http://doi.org/10.1145/2037556.2037602

Neirotti P, De Marco A, Cagliano AC, Mangano G, Scorrano F (2014) Current trends in smart city initiatives: Some stylised facts. Cities 38:25-36. http://dx.doi.org/10.1016/j.cities.2013.12.010

Niachou A, Papakonstantinou K, Santamouris M, Tsangrassoulis A, Mihalakakou G (2001) Analysis of the green roof thermal properties and investigation of its energy performance. Energy Build 33:719-729

Opti (2014) Advanced Green Roof Retrofit SAP North America Newtown Square, Pennsylvania. OptiRTC, Inc. https://d1qmdf3vop2107.cloudfront.net/turquoisetomato1.cloudvent.net/compressed/d6a9811ccafc0f498b7ac09ea692dc5d.pdf. Accessed 30 November 2016

Optigreen (2011) Technical Brochure Green Roofs. Optigrün.

https:/www.optigruen.de/fileadmin/contents/sprache_englisch_uk/Blaetterkatalog/index.html. Accessed 30 November 2016

Pincetl S, Bunje P, Holmes T (2012) An expanded urban metabolism method: Toward a systems approach for assessing urban energy processes and causes. Landsc Urban Plan 107:193-202.

http://dx.doi.org/10.1016/j.landurbplan.2012.06.006

Punkkinen H, Merta E, Teerioja N, Moliis K, Kuvaja E (2012) Environmental sustainability comparison of a hypothetical pneumatic waste collection system and a door-to-door system. Waste Management. 32: 1775-1781. http://dx.doi.org/10.1016/j.wasman.2012.05.003

Rovetta A, Xiumin F, Vicentini F, Minghua Z, Giusti A, Qichang H (2009) Early detection and evaluation of waste through sensorized containers for a collection monitoring application. Waste Manag 29:39-49. http://dx.doi.org/10.1016/j.wasman.2009.08.016

Teerioja N, Moliis K, Kuvaja E, Ollikainen M, Punkkinen H, Merta E (2012) Pneumatic vs. door-to-door waste collection systems in existing urban areas: A comparison of economic performance. Waste Manag 32:1782-1791. http://dx.doi.org/10.1016/j.wasman.2012.05.027

Townsend A (2013) SMART CITIES - Big data, civic hackers and the quest for a new utopia. W. W. Norton, New York.

VanWoert ND, Rowe DB, Andresen JA, Rugh CL, Xiao L (2005) Green roof stormwater retention: Effects of roof surface, slope and media depth. J Environ Qual 40:659-664. http://dx.doi.org/10.2134/jeq2004.0364

View Dynamic Glass. Product Guide. View. https://viewglass.com/assets/pdfs/product-guide.pdf. Accessed 30 November 2016 
View Dynamic Glass (2010) Energy benefits of View Dynamic Glass in workplaces. View. https://viewglass.com/assets/pdfs/workplace-white-paper.pdf. Accessed 30 November 2016

Villareal E, Dixon A (2005) Analysis of a rainwater collection system for domestic water supply in Ringdansen, Norrköping, Sweden. Build and environ 40: 1174-1184. http://doi.org/10.1016/j.buildenv.2004.10.018

Yang J, Yu Q, Gong P (2008) Quantifying air pollution removal by green roofs in Chicago. Atmos Environ 42:72667273

Zadeh SM, Hunt DVL, Lombardi DR, Rogers CDF (2013) Shared urban greywater recycling systems: Water resource

\section{Tables}

554 Table 1 The seven Smart City Solutions assessed in this study. The Solutions represent a broad number of domains within the building and ICT scope. The four domains represented are the building, waste, water and power domain.

\begin{tabular}{|c|c|c|c|}
\hline Solutions & $\begin{array}{l}\text { Dedicated } \\
\text { urban } \\
\text { solution }\end{array}$ & Description & Sources \\
\hline \multicolumn{4}{|c|}{ Building Domain } \\
\hline $\begin{array}{l}\text { Green } \\
\text { Roofs } \\
\text { (GRo) }\end{array}$ & No & $\begin{array}{l}\text { Roofing layer on flat roofs consisting of a plant layer and retention } \\
\text { layer, that can be automatically controlled. The retained water can be } \\
\text { stored in tanks and later used for purposes where non-drinking quality } \\
\text { is required. Results in reduction of water use and reducing air } \\
\text { pollution is due to the plant materials. Requires installation of new } \\
\text { mechanical system. }\end{array}$ & $\begin{array}{l}\text { (Optigreen 2011; Opti } \\
\text { 2014; Bianchini et al } \\
\text { 2012; Niachou et al 2001; } \\
\text { VanWoert et al 2005; } \\
\text { Yang et al 2008) }\end{array}$ \\
\hline $\begin{array}{l}\text { Smart } \\
\text { Windows } \\
\text { (SWi) }\end{array}$ & No & $\begin{array}{l}\text { A thin optical change film is installed in the windows on commercial } \\
\text { buildings. The film change by a voltage impulse, connected to a } \\
\text { manual and automatic control system. Resulting in electricity } \\
\text { reduction on air-conditioning and lighting, increasing energy use for } \\
\text { heating. Requires installation of new mechanical system. }\end{array}$ & $\begin{array}{l}\text { (View Dynamic Glass } \\
\text { n.d., 2010; Baetens et al } \\
\text { 2010; Free et al 2006) }\end{array}$ \\
\hline \multicolumn{4}{|c|}{ Waste Domain } \\
\hline $\begin{array}{l}\text { Sensorized } \\
\text { Waste } \\
\text { Collection } \\
\text { (SWC) }\end{array}$ & No & $\begin{array}{l}\text { The amount of waste in the garbage cans are measured by sensors. The } \\
\text { plan for the garbage trucks to empty the cans is made based in the } \\
\text { measurements. Resulting in a reduction in transport for waste } \\
\text { collection. Does not require installation of new mechanical system. }\end{array}$ & $\begin{array}{l}\text { (Enevo 2016; Mamun et } \\
\text { al 2014; Rovetta et al } \\
\text { 2009; Gutierrez et at } \\
\text { 2015) }\end{array}$ \\
\hline $\begin{array}{l}\text { Pneumatic } \\
\text { Waste } \\
\text { Collection } \\
\text { (PWC) }\end{array}$ & Yes & $\begin{array}{l}\text { Waste is transported by vacuum trough an underground piping system } \\
\text { to a collection terminal. The system is automatically controlled, when } \\
\text { the level waste in the inlets reach a certain level. Resulting in a } \\
\text { reduction in transport of waste. Requires installation of new } \\
\text { mechanical system. }\end{array}$ & $\begin{array}{l}\text { (Teerioja et al 2012; } \\
\text { Dansk skraldesug Aps } \\
\text { 2016; Envac ab 2009) }\end{array}$ \\
\hline \multicolumn{4}{|c|}{ Water Domain } \\
\hline $\begin{array}{l}\text { Greywater } \\
\text { Recycling } \\
\text { (GRe) }\end{array}$ & Yes & $\begin{array}{l}\text { Water from showers, wash basins etc. is collected in an extra loop, } \\
\text { cleaned and reused for purposes that requires non-drinking quality water. } \\
\text { The ICT make sharing of water between residential and commercial } \\
\text { buildings possible. Results in reduction of water use. Does not require } \\
\text { installation of new mechanical system. }\end{array}$ & $\begin{array}{l}\text { (Memon et al 2007; } \\
\text { Zadeh et al 2013; } \\
\text { Jefferson et al 2000; } \\
\text { Lazarova et al 2003) }\end{array}$ \\
\hline
\end{tabular}




\begin{tabular}{|c|c|c|c|}
\hline $\begin{array}{l}\text { Smart } \\
\text { Water } \\
\text { Meters } \\
\text { (SWM) }\end{array}$ & No & $\begin{array}{l}\text { Smart meters, receiving data from sensors connected to the water piping } \\
\text { system and accessing old data, is connected to the water piping system. } \\
\text { Now being able to detect leeks and make the consumers aware of their } \\
\text { water consumption. Resulting in a water reduction, due to reduced } \\
\text { leakage, and an electricity reduction due to the reduced amount of } \\
\text { transported water. Does not require installation of new mechanical } \\
\text { system. }\end{array}$ & $\begin{array}{l}\text { (Britton et al 2013; ITU } \\
\text { 2014; Kamstrup 2016a, } \\
\text { 2016b; Hauber-Davidson } \\
\text { et al 2006) }\end{array}$ \\
\hline \multicolumn{4}{|c|}{ Power Domain } \\
\hline $\begin{array}{l}\text { Smart } \\
\text { Energy } \\
\text { Grid (SEG) }\end{array}$ & No & $\begin{array}{l}\text { Smart meters, receiving data from heat sensors in the building, control } \\
\text { the heating based on availability of electricity as well as the heating } \\
\text { settings. The consumers are at the same time made aware of the } \\
\text { consumption. Resulting in a reduction in electricity use and an } \\
\text { electricity shift from coal produced to wind produced electricity. Does } \\
\text { not require installation of new mechanical system. }\end{array}$ & $\begin{array}{l}\text { (EcoGrid EU 2016; Hu et } \\
\text { al 2014; Malik et al 2013; } \\
\text { Chou et al 2016) }\end{array}$ \\
\hline
\end{tabular}

Table 2 The included impact categories, when the ReCiPe impact assessment method is used. For water depletion,

558 however, normalizations factors are all zero. Normalized and endpoint impact potentials for water depletion are

therefore not included in results. Results for Endpoint Damage and the midpoint category GWP is shown in the article.

Remaining results can be seen in supporting material.

\begin{tabular}{|ll|l|}
\hline \multicolumn{2}{|c|}{ Midpoint impact categories } & \multicolumn{1}{|c|}{ Endpoint categories } \\
\hline Agricultural land occupation potential & Metal depletion potential & Damage to human health \\
Global warming potential & Natural land transformation potential & Damage to ecosystems diversity \\
Fossil depletion potential & Ozone depletion potential & Damage to resources \\
Freshwater ecotoxicity potential & Particulate matter formation potential & availability \\
Freshwater Eutrophication potential & Terrestrial acidification potential & \\
Human Toxicity potential & Terrestrial ecotoxicity potential & \\
Ionizing radiation potential & Urban land occupation potential & \\
Marine ecotoxicity potential & Water depletion potential & \\
Marine eutrophication potential & & \\
\hline
\end{tabular}

Table 3 Main contributors to the impact potentials for the different Smart City Solutions. The parameters are based on hotspot and sensitivity analysis, conducted on all midpoint impact categories available when using ReCiPe. The stage of the parameter is indicated as either raw material and production stage or operation stage. The red color indicates that the parameter increase impact potential, while the green color indicates a reduction of impact potential. Parameters generally show reduction of impact potentials in operation stage, but increase in impacts in production stage.

\begin{tabular}{lcc}
\hline Smart City Solution & $\begin{array}{c}\text { Raw Material and Production } \\
\text { Stage Flows }\end{array}$ & Operation Stage Flows \\
\hline Green Roofs (GRo) & $\begin{array}{c}\text { Soil, Plastic, \& PVC } \\
\text { Avoided Heat from PVC } \\
\text { Incineration \& Soil Reuse }\end{array}$ \\
\hline Smart Windows (SWi) & ITO & \\
\hline Sensorized Waste Collection (SWC) & Sensor \& Controller & Avoided Electricity Use \\
\hline Pneumatic Waste Collection (PWC) & & Avoided Transport \\
\hline
\end{tabular}




\begin{tabular}{lcc}
\hline Greywater Recycling (GRe) & Electricity Use \\
\hline Smart Water Meters (SWM) & Sensor \& Controller & Avoided Electricity Use \\
\hline Smart Energy Grid (SEG) & Internet Access \& Sensor & Avoided Electricity Use \& \\
& & Avoided electricity produced by coal \\
\hline
\end{tabular}

Table 4 The relative change in impact potential for characterized midpoint category GWP and for the change in impact potential for the characterized endpoint categories damage to: Human Health, Resources, and Ecosystem. Negative change means that performance is improved from implementation of SCS.

\begin{tabular}{|c|c|c|c|}
\hline \multirow[b]{2}{*}{ Solutions } & \multicolumn{2}{|c|}{ Environmental Performance for Copenhagen } & \multirow[b]{2}{*}{ Comment } \\
\hline & $\begin{array}{l}\text { Global Warming } \\
\text { Potential (GWP) }\end{array}$ & Endpoint Damage & \\
\hline GRo & $+0,084 \%$ & $\begin{array}{l}\text { Smaller than }+0,5 \% \text { for all } \\
\text { categories }\end{array}$ & $\begin{array}{l}\text { The main contributors to the impact potentials } \\
\text { originate from materials use e.g. soil and plastic } \\
\text { needed for the mechanical construction. } \\
\text { Avoided/mitigated air pollution and water savings } \\
\text { only compensate for the material use to a limited } \\
\text { degree. }\end{array}$ \\
\hline SWi & $+75 \%$ & $\begin{array}{l}+70 \% \text { for Human Health } \\
+42 \% \text { for Resources and } \\
+46 \% \text { for Ecosystem }\end{array}$ & $\begin{array}{l}\text { The main contributor to impacts potentials is Use of } \\
\text { ITO between glazing. The material is of metallic } \\
\text { origin, relying on scarce resources. The reduction of } \\
\text { the electricity consumption only has very limited } \\
\text { compensatory impacts compared to the ITO material } \\
\text { induced impacts. }\end{array}$ \\
\hline SWC & $-0,17 \%$ & $-0,1 \%$ & $\begin{array}{l}\text { The main contributors to the impact potentials are } \\
\text { sensors and controllers, which both increase the } \\
\text { induced impacts, but no more than compensatory } \\
\text { impacts obtained from avoided transport. }\end{array}$ \\
\hline PWC & $+0,76 \%$ & $\begin{array}{l}+1 \% \text { for Resources and } \\
\text { smaller than }+1 \% \text { for } \\
\text { Human Health and } \\
\text { Ecosystem }\end{array}$ & $\begin{array}{l}\text { Electricity consumption to pneumatic pumps during } \\
\text { operation are the dominating contributor to the } \\
\text { impacts potentials. This electricity consumption } \\
\text { induced impacts largely outweighs the savings from } \\
\text { avoided transport. }\end{array}$ \\
\hline GRe & $+0,70 \%$ & $\begin{array}{l}+1 \% \text { for Resources and } \\
\text { smaller than } 1 \% \text { for Human } \\
\text { Health and Ecosystem }\end{array}$ & $\begin{array}{l}\text { Electricity use during operation for the water pumps } \\
\text { is the main contributor to the impact potentials. This } \\
\text { electricity consumption induced impacts largely } \\
\text { outweighs the savings from avoided water use. }\end{array}$ \\
\hline SWM & $-0,024 \%$ & $\begin{array}{l}\text { Smaller than }+0,1 \% \text { for } \\
\text { Human Health and } \\
\text { Resources, and smaller than } \\
-0,1 \text { for Ecosystem }\end{array}$ & $\begin{array}{l}\text { Indicates that midpoint impact potentials only exhibit } \\
\text { performance improvement in some categories. Main } \\
\text { contributors to induced impacts are sensors and } \\
\text { controllers, while avoided electricity use accounts for } \\
\text { the avoided impacts. }\end{array}$ \\
\hline SEG & $-10 \%$ & $\begin{array}{l}-4,8 \% \text { for Human Health } \\
-3,0 \% \text { for Resources and } \\
-9,0 \% \text { for Ecosystem }\end{array}$ & $\begin{array}{l}\text { The main contributor to avoided impacts potentials is } \\
\text { the reduced electricity consumption while internet } \\
\text { access component increase accounts for the majority }\end{array}$ \\
\hline
\end{tabular}




\section{Figure Captions}

Figure 1 The Geographical scope of the analysis: The municipality of Copenhagen and Frederiksberg, marked with grey.

Figure 2 The metabolic flows used as input for the operation stage in the UM-LCA. The figure is inspired from (Goldstein et al. 2013).

Figure 3 A City UM-LCA model. The stage methodology from LCA adds to the typical UM of cities to give a more complete picture of the city's impact potential. The metabolic flows work as input for the operation stage and the metabolic fates work as input for the EoL stage. The figure is inspired from (Goldstein et al. 2013).

Figure 4 The UM-LCA model for the Smart City Solutions. The modelling of the Smart City Solution is made like a product LCA. Using material compositions and use data as input.

Figure 5 Illustration of the system boundaries for Copenhagen and the Smart City Solutions modelling. The direct and embedded impacts excluded from the system is marked with red, while the direct impacts included marked with black

Figure 6 An example of the "100\% implementation" of the Smart City Solution for Green Roofs. The results for Green Roof implementation are scaled from an investigation of a smaller area in Copenhagen (Municipal of Frederiksberg), and represents the complete, but realistic implementation of a solution in the urban area.

Figure 7 Characterized midpoint results for a) GWP [kg CO 2 -eq.] calculated using ReCiPe 2008 v. 1.11 Hierarchist. 
Copenhagen and for the scenarios where Smart City Solutions are introduced individually. Results are calculated for the year 2013 .

Figure 8 Illustrating the burden shifting that happens when implementing Smart City Solutions in Copenhagen. The illustration of the change in size of the burden is not in scale to the calculated impact potential.

\section{Figures}

Figure 1:

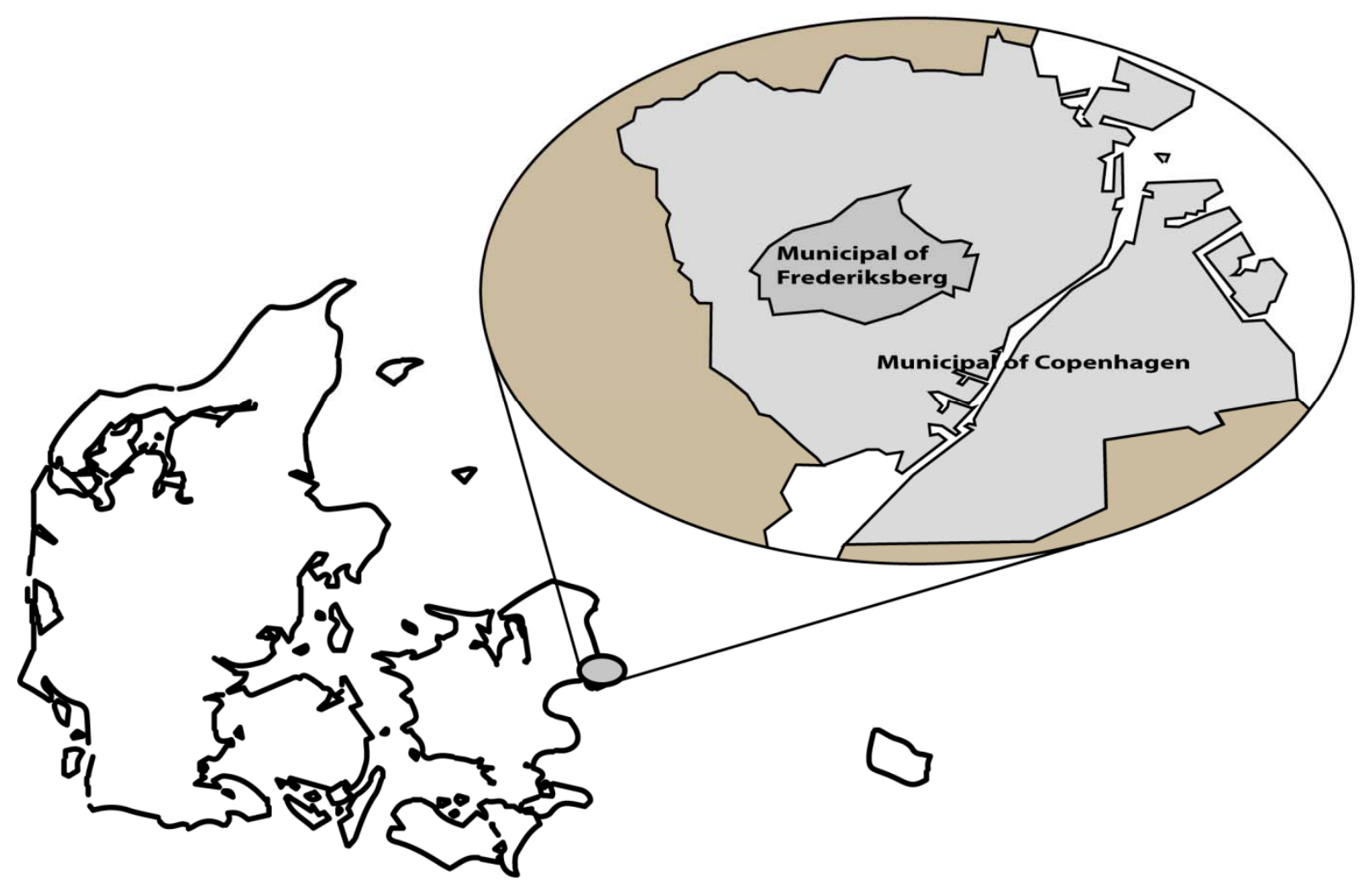

Figure 2: 


\section{METABOLIC FLOWS}

Food: vegetables, fruits, juice, meat, fish, eggs, dairy, grains, sugar, tea, coffee, cigarettes, alcoholic beverage

Water: residential, commersial, industrial

Transport: private (car, motorcycle, cycle), public (train, bus), freight (train, lorry)

Building energy: electricity, thermal energy (heating), oil and gas

Metals: steel, iron, aluminum, precious metals

Plastics: polyvinylchloride, mixed plastic

Paper: newsprint, cardboard

Glass: white/clear, green, brown (all packaging)

Rubber: natural, synthetic

Electronics: white goods (stove, fridges etc.), consumer electronics (labtops, tv's etc.), batteries, PV-panels

Construction materials: concrete, wood, bricks, plastics, steel, processed firbre producs, windows, insulation

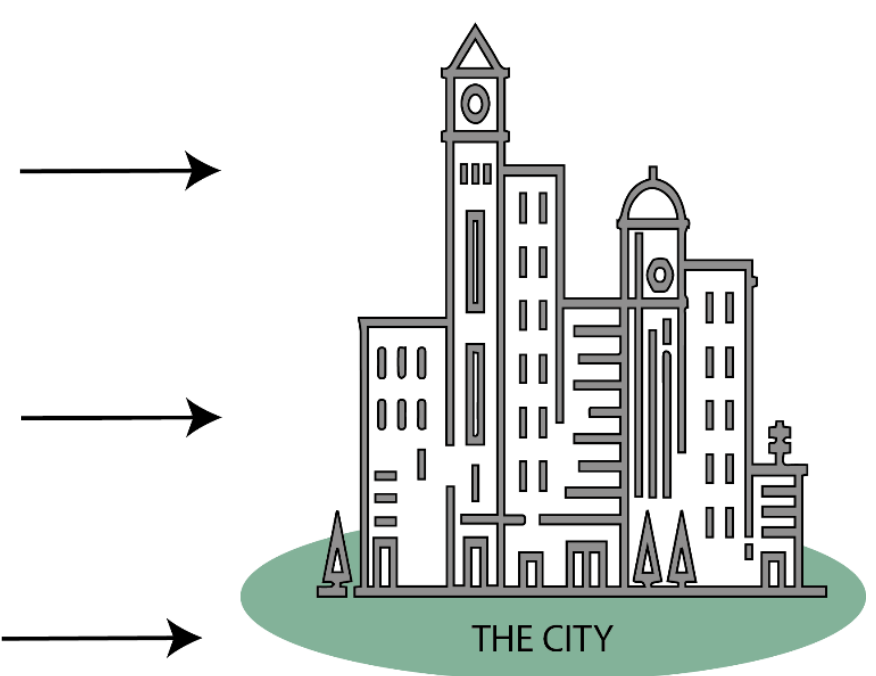

Figure 3:

612

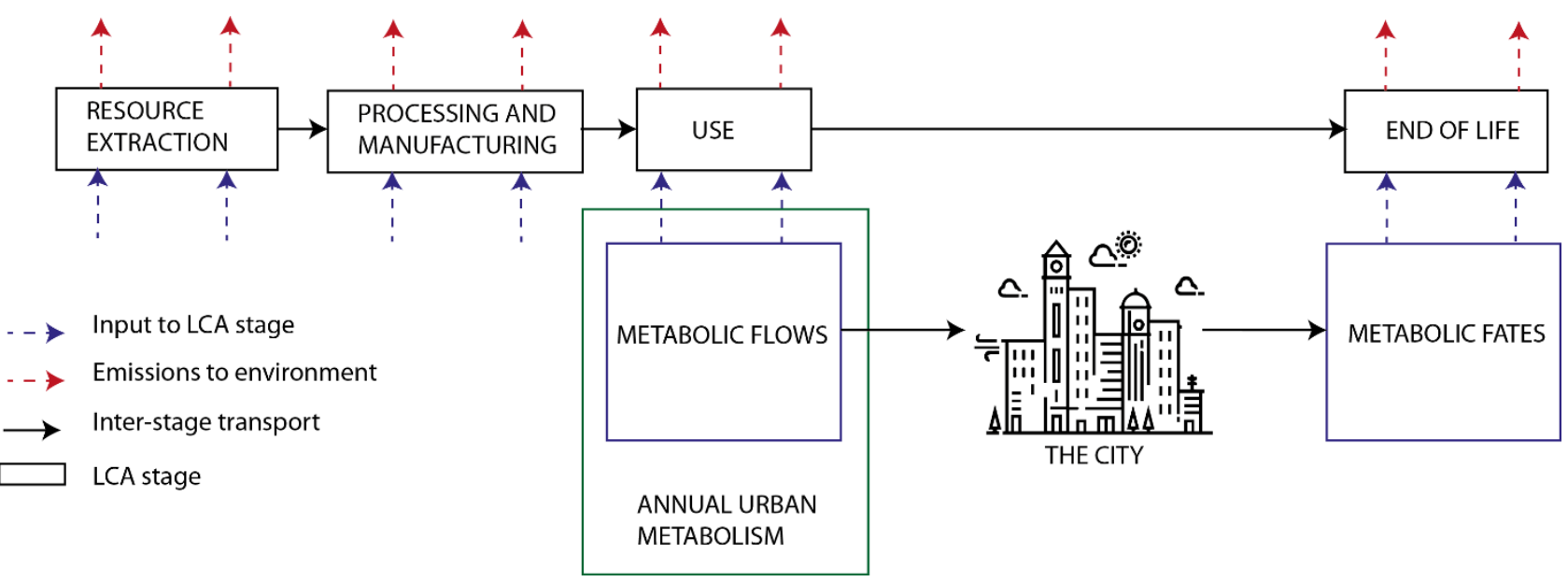

613

Figure 4:

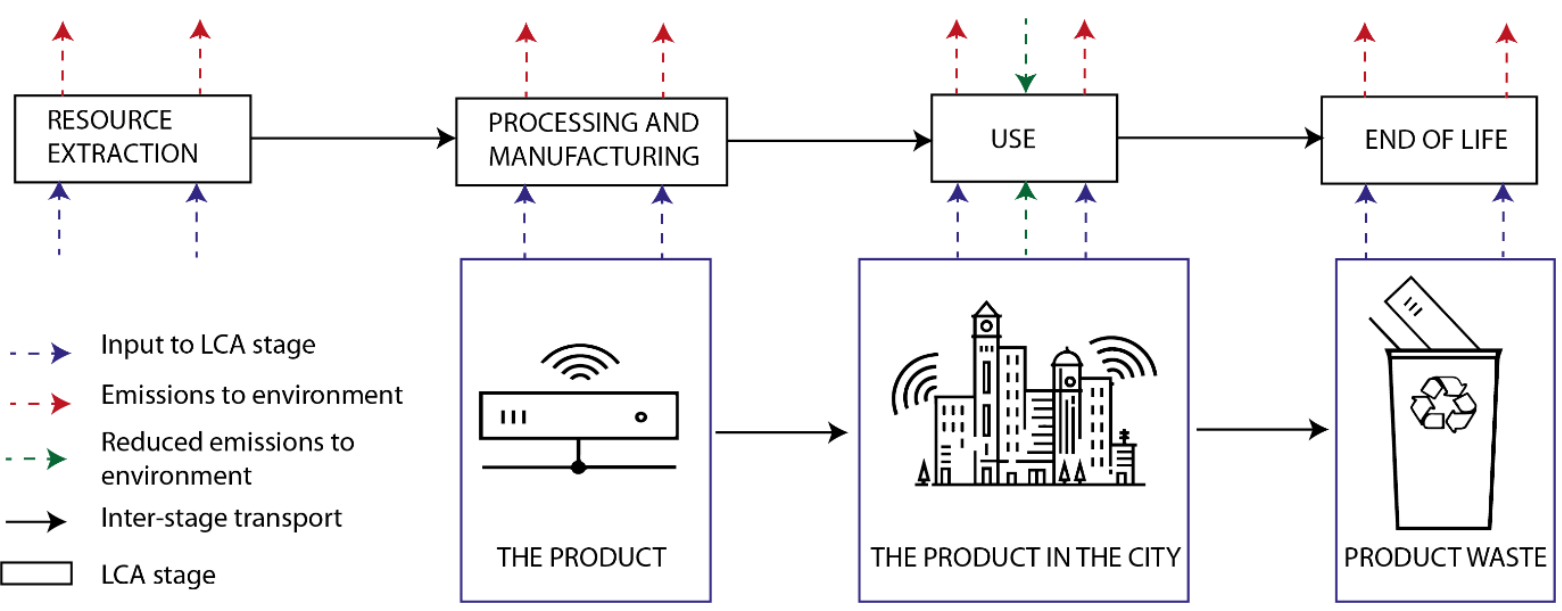

Figure 5: 


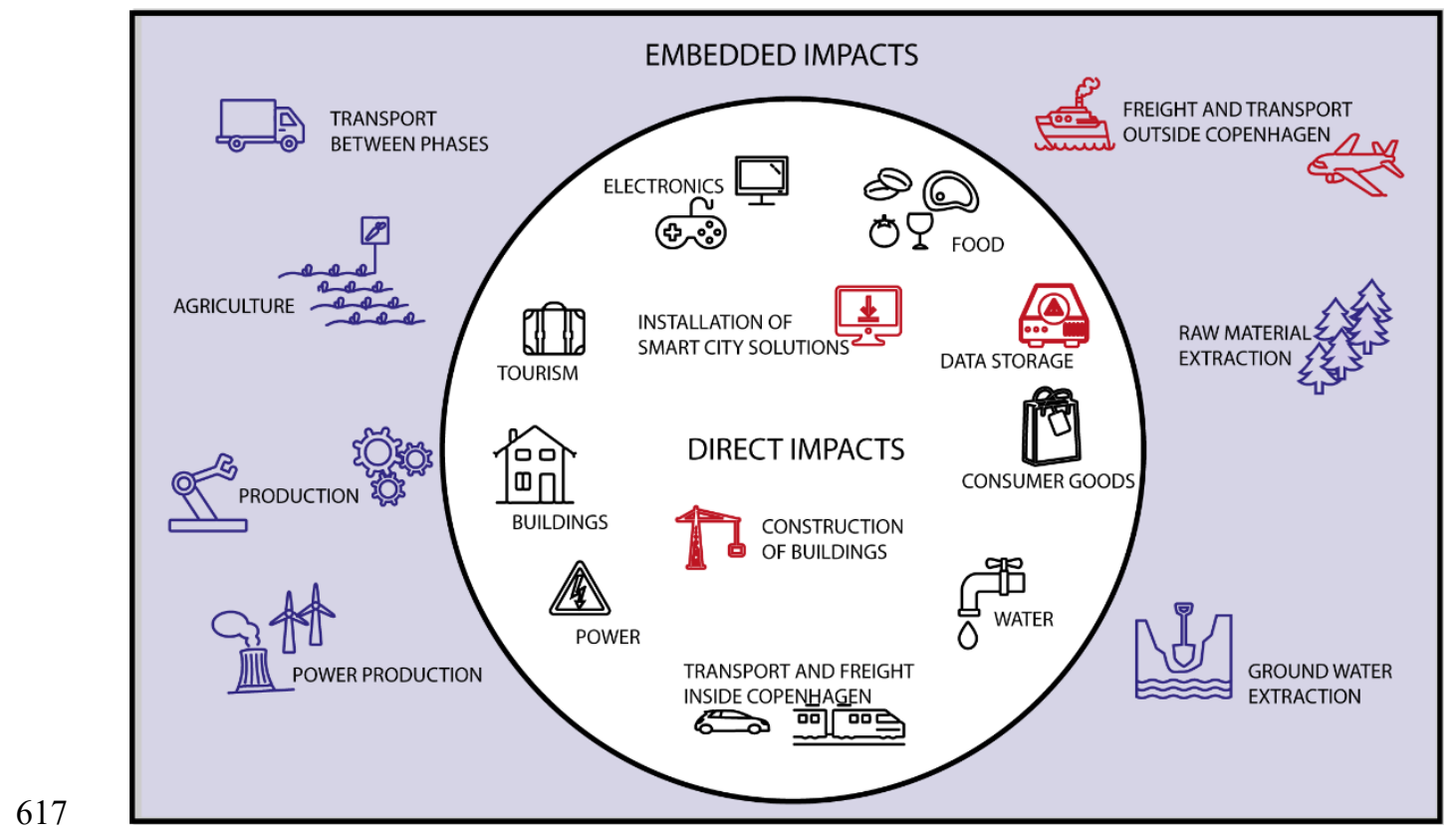

618

619

620

Figure 6:

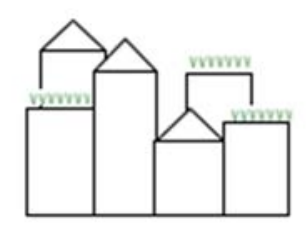

Frederiksberg Municipality investigation of roofs suitable for Green Roof implementation

\section{Green Roof: 100}
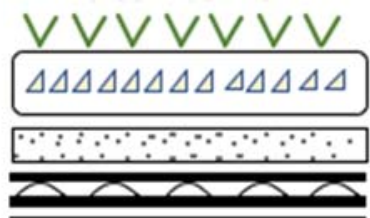

621

622

Figure 7:

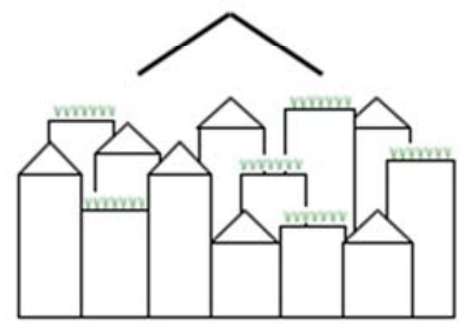

Upscaling to Copenhagen

$100 \%$ implementation in

Copenhagen 
a)

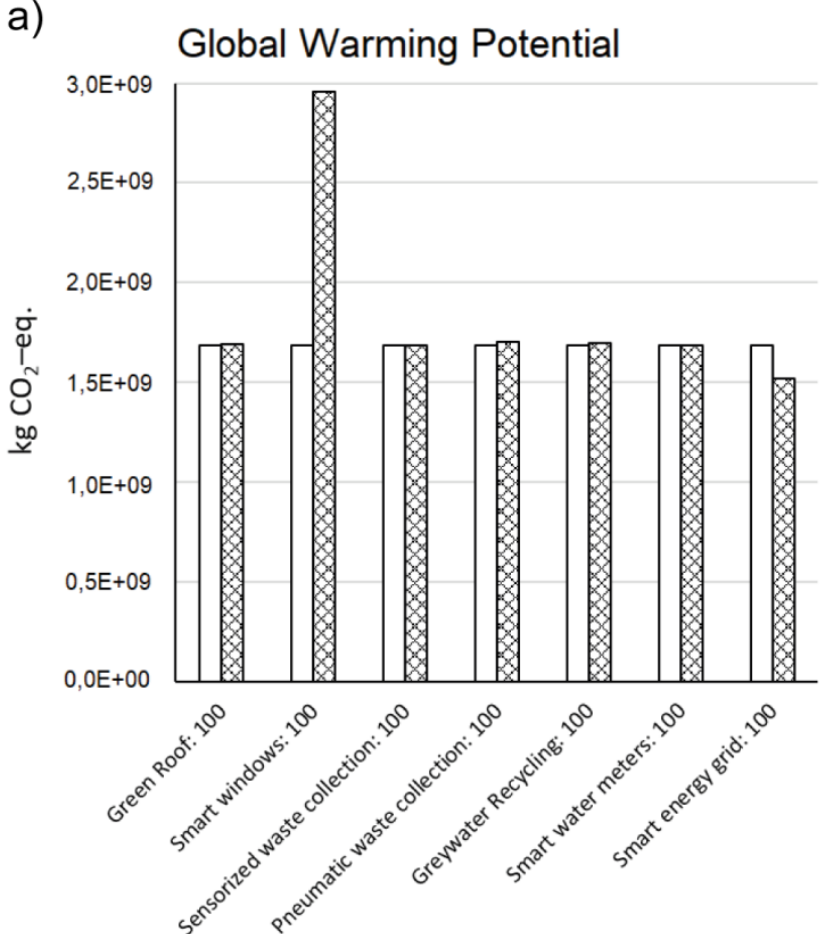

c)
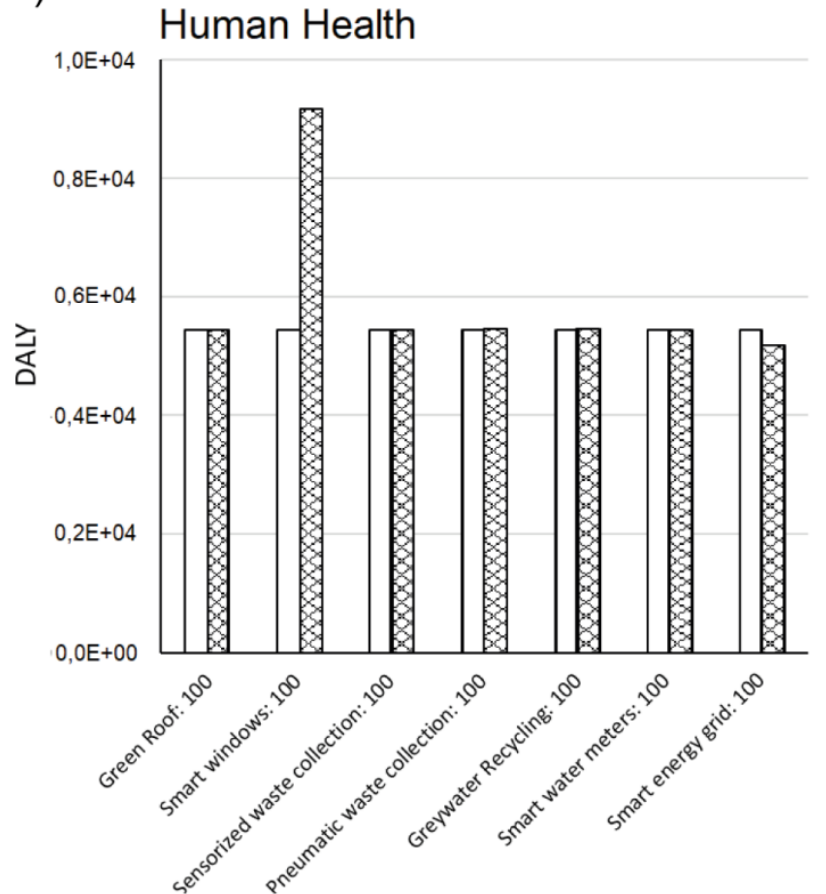
Copenhagen

$8 \times$ Smart Copenhagen b)

Ecosystems

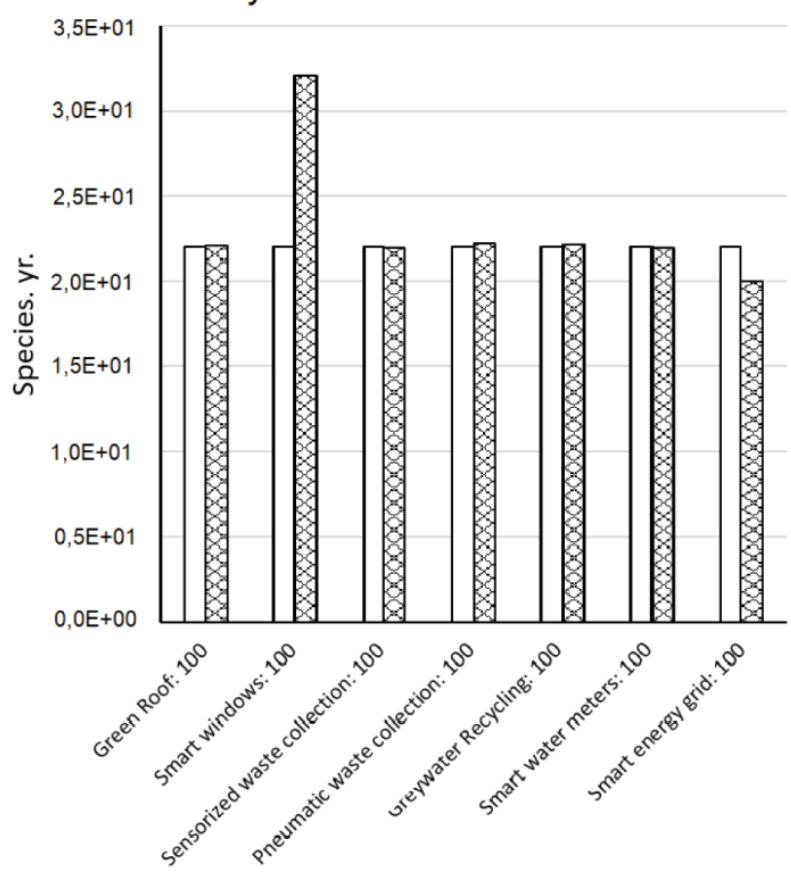

d)

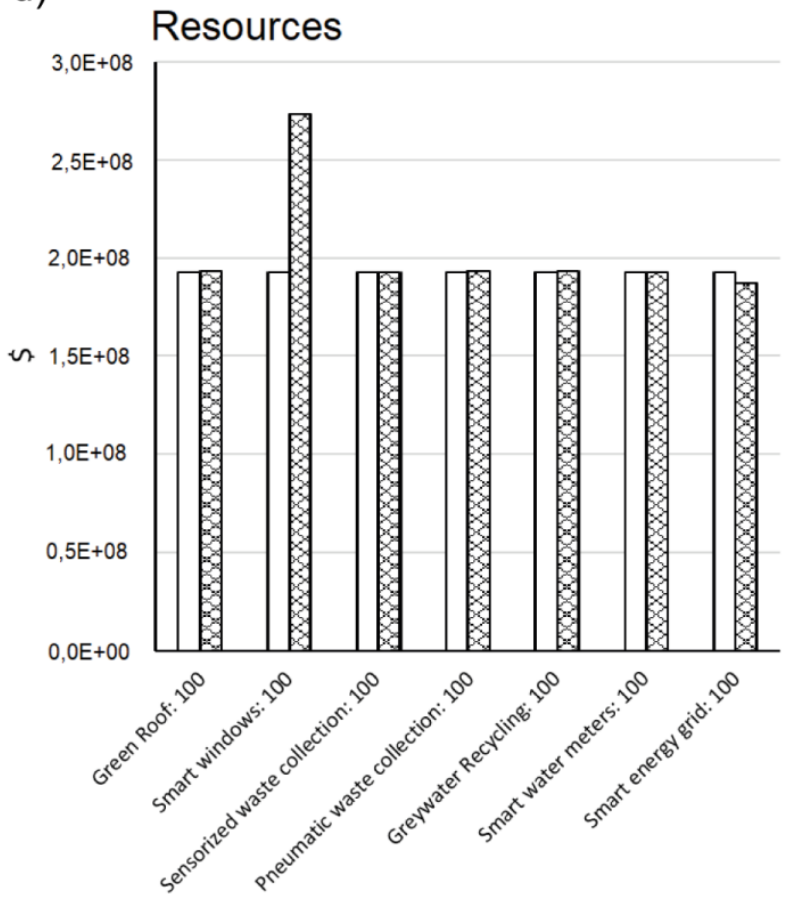


630 Figure 8:

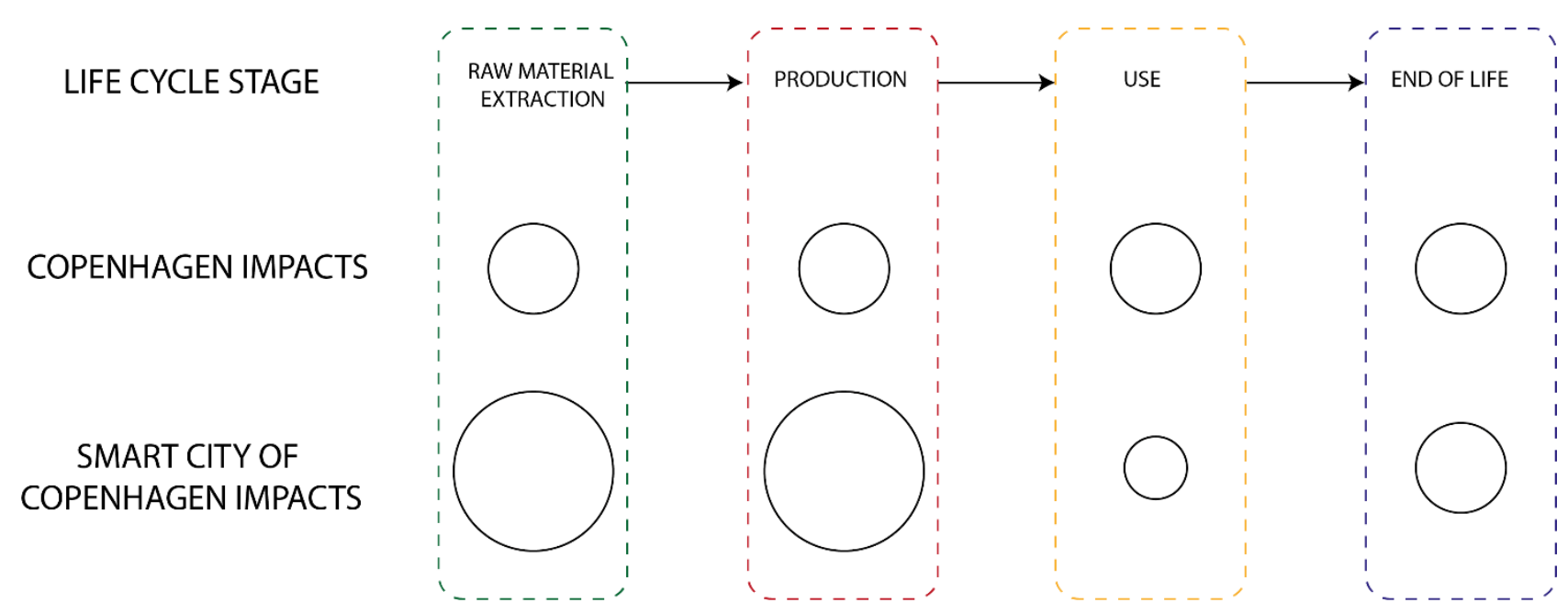

